\title{
The Outpatient Burch-Sling Procedure: A Nerve-Sparing Method for Correcting Female Urinary Incontinence
}

\author{
Daryoosh Samimi*, John S. Samimi\# \\ Department of Ob-Gyn, Keck School of Medicine, USC, U.S. Women Institute, Fountain Valley, CA, USA \\ Email: alfacreative@earthlink.net
}

How to cite this paper: Samimi, D. and Samimi, J.S. (2017) The Outpatient Burch-Sling Procedure: A Nerve-Sparing Method for Correcting Female Urinary Incontinence. Open Journal of Urology, 7, 243-251.

https://doi.org/10.4236/oju.2017.712029

Received: March 6, 2017

Accepted: December 11, 2017

Published: December 14, 2017

Copyright ( 92017 by authors and Scientific Research Publishing Inc. This work is licensed under the Creative Commons Attribution International License (CC BY 4.0).

http://creativecommons.org/licenses/by/4.0/

\begin{abstract}
Conventional methods to treat urinary stress incontinence, including the Sling, Burch, and Pereyra modification methods, are limited by several shortcomings due to disrupted nerve and vaginal wall integrity. The nerve-sparing Burch-Sling method represents a surgical advancement through the use of a nerve-sparing sling to treat genuine stress urinary incontinence. The procedure involves retropubic urethropexy using the FDA-approved Burch-Sling device. In this technique, the vagina is elevated bilaterally at the urethrovesical junction to the mid-urethra toward Cooper's ligament above the base of the bladder. Then, the anterior vaginal wall and fascia are used as an endogenous suburethral sling without dissection. Two hundred twenty cases were included in this study; two hundred patients underwent the outpatient nerve-sparing sling method, and the other twenty underwent the novel abdominal Burch method. There were no major complications. The follow-up duration ranged from 6 months to eight years. All procedures were performed at the U.S. Women's Institute at a 400-bed hospital in Fountain Valley, CA.
\end{abstract}

\section{Keywords}

Outpatient Sling Procedure, Burch-Sling Device "FDA", Novel Burch Procedure, Nerve-Sparing Method, Preservation of Vaginal Nerve Plexus, Preservation of External Nerve of Urethra, Minimizing Complications, Reduce Financial Burden

\section{Introduction}

Urinary incontinence has been reported to affect $10 \%-25 \%$ of women under the

`Daryoosh Samimi, M.D. Academic Rank: Professorship.

"John S. Samini, PharmD, Consultant Pharmacist. 
age of $65,15 \%-30 \%$ of non-institutionalized women over age 60 and more than $50 \%$ of nursing home residents. The incidence of the disorder is expected to increase as the population ages. Operative techniques should be reserved for women who decline conservative therapies or do not improve with such treatments. Ideally, female candidates for operative techniques should have completed childbearing. The patients are females with an average age of 65. Existing corrective surgical procedures for stress urinary incontinence include anterior colporrhaphy (Kennedy-Kelly plication), various suburethral sling procedures, vaginal needle suspensions (Pereyra, Stamey and Gittes procedures), retropubic urethropexy and urethral slings (Tension Free Vaginal Tape (TVT) and Trance Obturator Tape (TOT)).

Anterior colporrhaphy corrects urethral hypermobility but may not provide adequate long-term support of the urethrovesical junction. Another traditional correction method is the suburethral sling. In this technique, the urethra is exposed by a midline incision, and lateral tunnels at the level of the bladder neck are made by a combination of careful sharp and blunt dissections. All textbook versions of the Pereyra method, with the exception of the Gittes procedure, involve extensive anterior wall dissection up to the pubic bone. In addition, all variations of this technique involve anchoring the suspension sutures to the rectus fascia through a suprapubic incision. However, the currently most commonly performed procedures, including the mid-urethral sling, are not nerve sparing due to surgical opening of the vaginal wall and introduction of a 6 -mm-diameter needle [1] [2].

\section{Methods}

Outpatient nerve-sparing sling. After obtaining diagnostic confirmation and patient consent, appropriate anesthesia is administered. The patient is placed in a modified lithotomy position. The lower abdomen and pelvis are prepped and draped in a routine manner. After pelvic examination, a weighted speculum is placed into the vagina.

Bladder evacuation is performed with a Foley catheter (No. 14). The Foley catheter bulb is fixed inside the bladder after injecting $8-10 \mathrm{~mL}$ of sterile water. Traction on the Foley catheter facilitates the identification of the urethrovesical junction.

A No. 2 non-absorbable suture is placed under the vaginal mucosa, $1-1.5 \mathrm{~cm}$ lateral to the urethrovesical junction, using a Mayo needle. The same procedure is repeated on the opposite side (Figure 1). Next, $2-2.5-\mathrm{cm}$ transverse incisions are made bilaterally on top of the bony edge of the pectineal line, approximately $3 \mathrm{~cm}$ lateral to the midline. This incision placement avoids injuring major vessels. The incision continues until the bony edge of the pectineal line (Figure 2).

The Burch-Sling Device, which has a double-pronged stylet with a sleeve and ligature carrier, is gently positioned and passed through the bony edge of the 


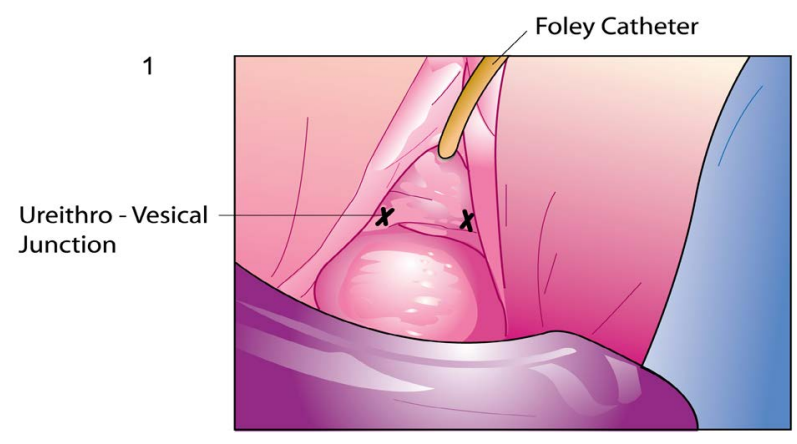

Figure 1. The urethrovesical junction.

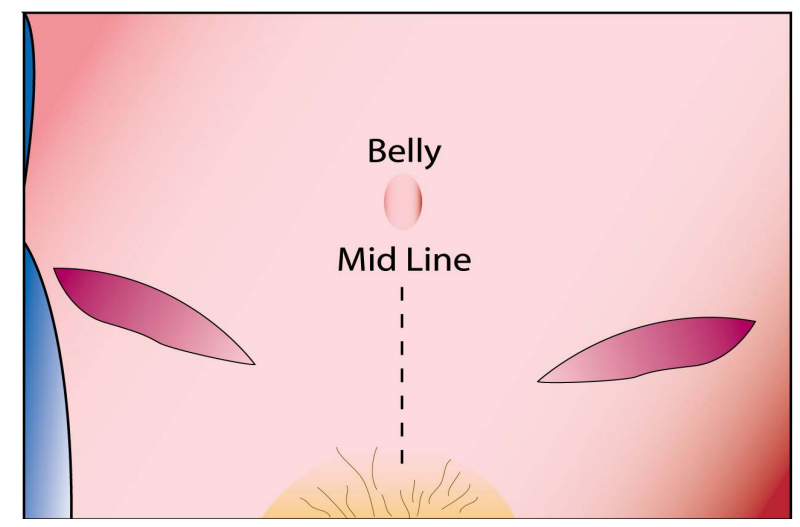

Figure 2. Bilateral suprapubic incision.

pectineal line (Figure 3) and Retzius' space under direct finger guidance. The double-pronged stylet is then withdrawn, and the sleeve is left in place (Figure 4). The ligature carrier is then passed through the inner sleeve of the Burch-Sling Device. One end of the previously placed suture is threaded through the eye of the ligature carrier (Figure 5), withdrawn to the inner side of the suprapubic incision and tagged with a hemostat clamp. The ligature carrier is then passed through the outer sleeve of the Burch-Sling Device, and the other end of the suture is brought to the outer side of the suprapubic incision (Figure 6). The same procedure is repeated on the opposite side. Tying the suspension sutures should be delayed until after cystoscopy (Figure 7).

Cystourethroscopy is then performed to ensure that the bladder has not been injured. Rigid cystoscopy helps confirm that the urethra and bladder neck have received adequate support. The lateral aspect, particularly the 3 and 9 o'clock views of the urethrovesical junction and lower bladder, must be clearly observed with no oozing, bleeding, or suture violation. If the suspension sutures have penetrated the bladder wall, they should be removed, and the procedure should be repeated [3] [4].

The suprapubic bladder catheter is placed using cystoscopy to verify its intravesical position. The last step involves tying the suspensory sutures on top of the pectineal or Cooper's ligament (Figure 3). It is strongly recommended that the surgeon use their own fingers to elevate the urethrovesical junction. Moderate 


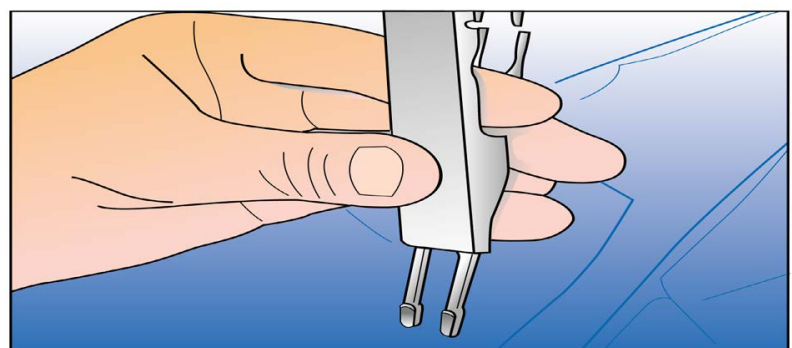

Figure 3. Burch-Sling device is gently positioned at the edge of the iliopectineal line.

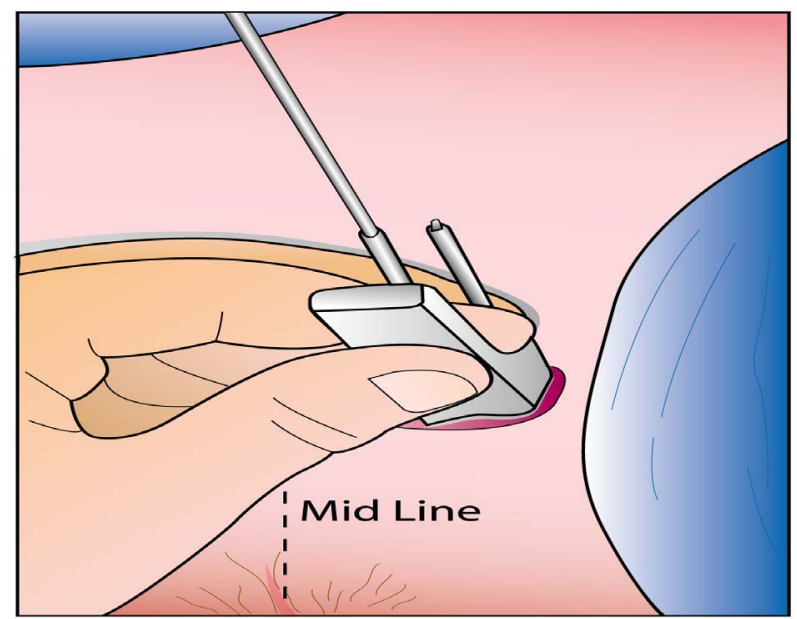

Figure 4. The double-pronged stylet is withdrawn and the double-pronged sleeve is left in place. The ligature carrier is then passed through the inner sleeve of the Burch-Sling.

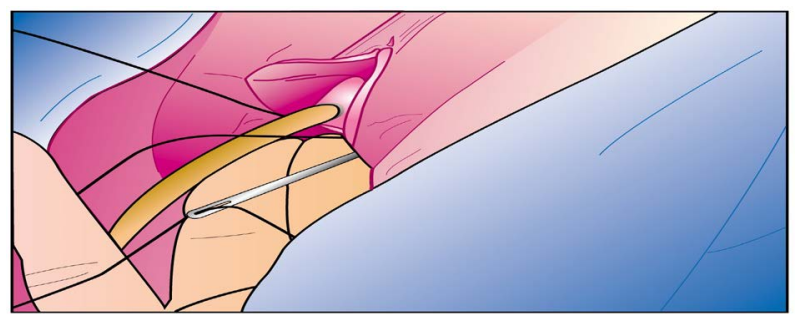

Figure 5. One end of the previously placed suture is threaded through the eye of the ligature carrier.

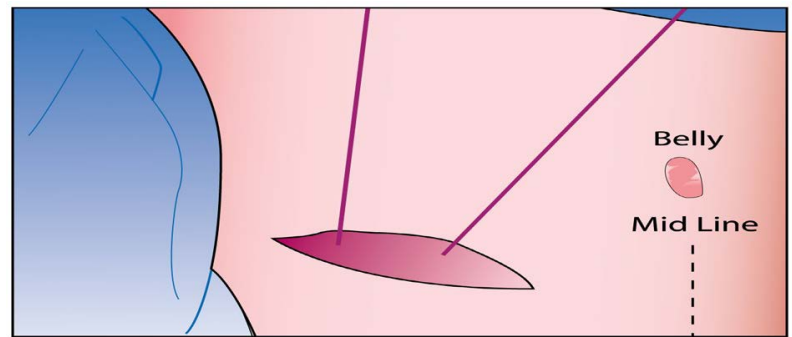

Figure 6. The ligature carrier is then passed through the outer sleeve of the Burch-Sling device, and the other end of the suture is brought to the outer side of the suprapubic incision. 
tension is required when tying the suspension suture to provide the support necessary to treat stress urinary incontinence (Figure 8; DVD).

\subsection{Novel Abdominal Burch Procedure}

In total, 20 patients underwent the novel abdominal Burch method [5]. The Burch method can be performed after any abdominal surgery (i.e., hysterectomy or laparotomy) [5] [6]. In the conventional Burch method [7], suspension sutures are fixed abdominally after blunt dissection of Retzius' space. Consequently, the surgeon has considerable difficulty affixing the abdominal suspension sutures to the endopelvic fascia due to poor visibility and active bleeding in Retzius' space. Moreover, potential ureter and bladder injuries represent major patient safety risks.

Vaginal fixation of the suspension sutures eliminates these risks. Suspension sutures are fixed vaginally on the lateral side of the urethrovesical junction to the mid-urethra (Figure 7; video). The sutures are buried under the vaginal mucosa without vaginal dissection, fixed under the endopelvic fascia and brought to the bilateral edges of the pectineal line using the Burch-Sling device (Figure 7 and Figure 8; DVD).

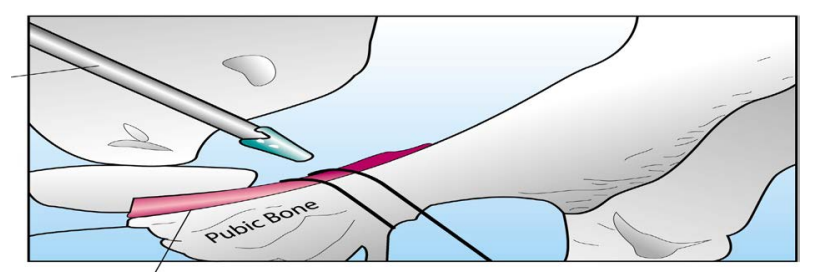

Figure 7. The suspension suture should be tied after cystoscopy.

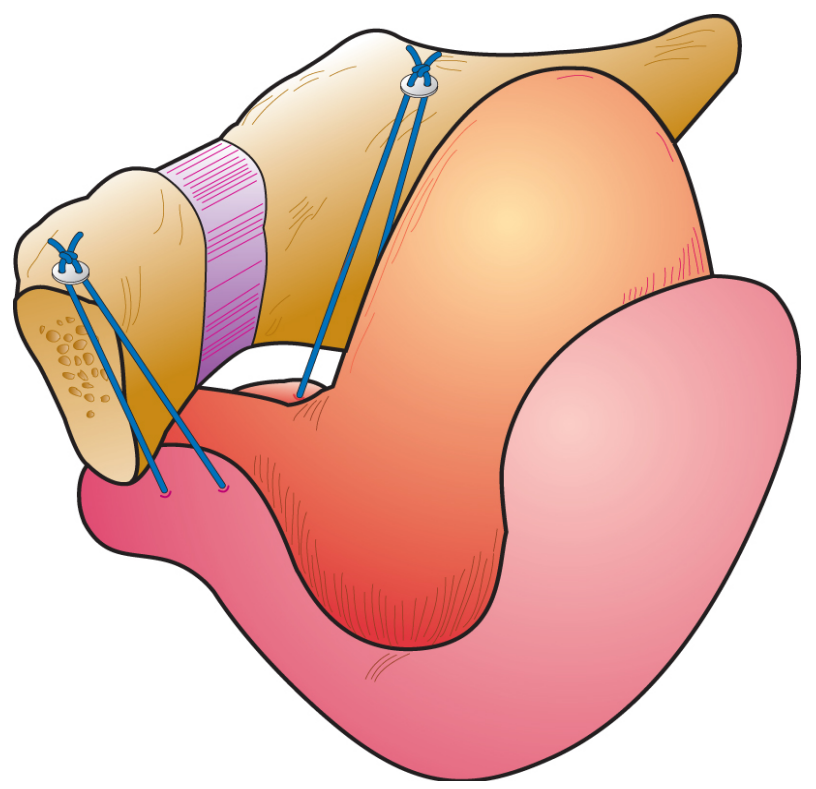

Figure 8. Suspension sutures fixed under the endopelvic fascia are anchored to the pectineal line or Cooper's ligament. 


\subsection{Experience}

Two hundred twenty patients with confirmed genuine stress urinary incontinence were admitted to our urinary incontinence clinic between January 1997 and January 2015. The diagnosis of stress urinary incontinence was confirmed by well-established criteria [8] [9]. A complete history, including an accurate incontinence history with urodynamic testing and a physical history, was obtained. The mean age of the patients was 57.5 years (range: 33 to 83 years), and the mean weight was 185 pounds [5]. Of these patients, two hundred underwent an outpatient nerve-sparing sling procedure [10] [11]. The other twenty patients underwent the novel abdominal Burch procedure (Table 1). The FDA-approved Burch-Sling device was employed for all the surgeries. The total operation time averaged 40 minutes.

The success rate at three years after correction was more than $90 \%$, with only six failures. No patient experienced suture abscess or wound infection. There were no postoperative vaginal granulomas, vesicovaginal fistulas, hematomas or nerve damage. Self-catheterization was not needed, and there were no cases of osteitis pubis.

No patients were readmitted to the hospital for urinary tract problems. Long-term follow-up of the endogenous sling used for retropubic urethropexy revealed no required revisions due to loosening of the suspension sutures.

\section{Discussion}

The main symptoms and complaints are involuntary loss of urine with social and hygienic problems and objectively demonstrable.

Over the past forty years, many studies have shown that the Burch procedure is better [12] [13] and less traumatic than various needle or sling procedures. The likelihood of nerve damage is greater during traditionally incontinence procedures because of extensive anterior vaginal wall dissection. The surgical opening and dissection employed in the mid-urethral sling technique increase the risk of somatic and automatic nerve fiber damage [14] [15].

Furthermore, the long-term success rate of vaginal needle suspensions may be compromised due to the tendency of the sutures to pull through the rectus fascia, as this tissue is weaker compared with the pectineal or Cooper's ligament. In addition, the greatest objection to the modified Pereyra procedures is that extensive dissection and pubourethral suturing may produce significant bleeding and poor visibility and thus could cause urethral denervation or devascularization.

Awareness of the precise anatomical location of the somatic and autonomic nerve supply to the urethral sphincter [16] [17] and vaginal nerve plexus is vital for avoiding injury during needle suspension or TVT procedures. A general lack of neuroanatomical knowledge renders these nerve branches susceptible to injury during dissection. Kulva and Nilsson presented an analysis of TVT complications [18] [19] in Finland based on 1455 cases at 38 hospitals. The long-term results of TVT for mixed and stress urinary incontinence indicate that good 
Table 1. Incidence of complications for mid-urethral TVT vs. Outpatient nerve-sparing sling technique (author's own experience).

\begin{tabular}{|c|c|c|}
\hline & Mid-urethral TVT & $\begin{array}{l}\text { Outpatient Burch Sling } \\
\text { Technique }\end{array}$ \\
\hline $\begin{array}{l}\text { Difficulty voiding residual urine of more than } \\
100 \mathrm{cc} \text { lasting } 48 \text { hours to } 4 \text { months }\end{array}$ & $2.3 \%$ & $0 \%$ \\
\hline $\begin{array}{l}\text { Complete urinary infection } \\
\text { lasting } 6 \text { hours to } 6 \text { months }\end{array}$ & $7.5 \%$ & $0 \%$ \\
\hline Urinary tract infection & $4.1 \%$ & $1 \%$ \\
\hline Bladder perforation & $3.8 \%$ & $0 \%$ \\
\hline $\begin{array}{l}\text { Retropubic hematoma } \\
\qquad(3 \text { to } 10 \mathrm{~cm})\end{array}$ & $10.9 \%$ & $0 \%$ \\
\hline Reduced or poor health & $0.9 \%$ & $0 \%$ \\
\hline Post-operative hematoma & $1.7 \%$ & $0 \%$ \\
\hline Nerve injury & $0.9 \%$ & $0 \%$ \\
\hline Infection associated with erosion & $12 \%$ & $0 \%$ \\
\hline Vaginal abscess requiring drainage & $0.7 \%$ & $0 \%$ \\
\hline $\begin{array}{l}\text { Ischiorectal fossa abscess at approximately } 2 \\
\text { months post-procedure requiring drainage }\end{array}$ & $1.4 \%$ & $0 \%$ \\
\hline Infection of nonspecific etiology & $3.5 \%$ & $0.7 \%$ \\
\hline
\end{tabular}

initial cure rates do not persist after 4 years. Moreover, the TVT procedure carries the risk of major vascular injury [20] [21].

\section{Conclusions}

We have demonstrated that the nerve-sparing sling procedure can be performed on an outpatient basis with minimal to no postoperative complications. It has been demonstrated that avoiding dissection of the anterior vaginal walls preserves the nerves while correcting urinary incontinence. This new outpatient surgical sling approach for correcting genuine stress urinary incontinence specifically prevents injuries to somatic nerve fibers, such as the external urethral sphincter nerve and the vaginal nerve from the autonomic nerve division [22]. Other notable features of this technique include the utilization of an endogenous sling for colpourethropexy and the edge of the pectineal line for anchoring the suspension sutures. The Burch-Sling device enables the suspension sutures to be fixed directly to the edge of pectineal ligaments under the vaginal mucosa and endopelvic fascia.

We described herein the outpatient sling and novel abdominal Burch techniques for the treatment of genuine stress urinary incontinence. One unique feature of the outpatient sling technique is the absence of anterior vaginal wall dissection. The use of the anterior vaginal wall and endopelvic fascia as an endogenous sling for colpourethropexy [23] and the anchoring of suspension sutures to the pectineal line are distinguishing features. We also introduced the novel abdominal Burch technique, which involves vaginal fixation by suspension sutures directly under the vaginal mucosa and endopelvic fascia towards Coop- 
er's ligament. Suspension sutures are brought to the edge of the pectineal line abdominally by using the Burch-Sling Device. Both techniques minimize post-operative complications relative to conventional approaches for correcting genuine stress urinary incontinence with improved outcomes. We emphasize that proper instruction and training are necessary to perform these methods. Receiving informed consent from the patient to report this paper is a must.

\section{References}

[1] Samimi, D. (1998) The Closed Burch Procedure Outpatient with No Laparotomy or Laparoscopy. ACOG ACM, New Orleans, LA.

[2] Tamussuino. K.F., et al. (2002) Tension-Free Vagina Tape Operation Obstetric. Gynecology, 98, 732-736.

[3] Samimi, D. (2002) VHS Short Film: Outpatient Burch-Sling Procedure-A Nerve a Sparing Method for Correction of Female Urinary Incontinence. ACOG ACM, Los Angeles, CA.

[4] Novick, A. (1989) Stewart's Operation Urology. 2nd Edition, William \& Wilkins, Baltimore.

[5] Samimi, D. (2003) Randomized Clinical Trial of Intrastromal Abdominal Hysterectomy, Bloodless Nerve Sparing TAH. ACOG ACM, New Orleans, LA.

[6] Shafik, A. and Doss, S. (1999) Surgical Anatomy of the Somatic Terminal Innervations the Anal and Urethral Sphincters: Role in Anal and Urethral Surgery. Journal of Urology, 161, 85-89. https://doi.org/10.1016/S0022-5347(01)62072-X

[7] Drukker, B. and Miller Jr., D. (1978) Retropubic Urethropexy by the Vaginal Wall Technique in Stress Urinary Incontinence. Clinical Obstetrics and Gynecology, 21, 775-785. https://doi.org/10.1097/00003081-197809000-00013

[8] Karan, M.M., Segal, J.L., et al. (2003) Complications and Untoward Effects of the TVT Procedure. Obstetrics \& Gynecology, 101, 929-932.

[9] Kuava, N. and Nilsson, C.G. (2002) A Nationwide Analysis of Complications Associated with the Tension-Free Vaginal Tape (TVT) Procedure. Acta Obstetricia et Gynecologica Scandinavica, 81, 72-77.

[10] Samimi, D. (2002) Outpatient Burch-Sling Procedure-A Nerve Sparing Method for Correction of Female Urinary Incontinence. ACOG ACM, Los Angeles, CA.

[11] Laurikainen, E., Valpas, A., Kivela, A., et al. (2007) Retropubic Compared with Transobturator Tape Placement in Treatment of Urinary Incontinence: A Randomized Controlled Trial. Obstetrics \& Gynecology, 109, 4-11.

[12] Richter, H.E., et al. (2008) Two-Year Outcomes after Surgery for Urinary Incontinence in Older Women. Obstetrics \& Gynecology, 112, 621.

[13] Kalorin, C.M., et al. (2009) Complete Eversion of the Urinary Bladder: Presentation, Review, and Algorithm for Management. Obstetrics \& Gynecology, 113, 496-501. https://doi.org/10.1097/AOG.0b013e318184ee8b

[14] Samimi, D. (2011) Abstract the Outpatient Burch-Sling Procedure: A Nerve Sparing Method for the Correction of Female Urinary Incontinence. IUGA, 24 March 2011.

[15] Jonsson Funk, M., Siddiqui, N.Y., Kawasaki, A., et al. (2012) Long-Term Outcomes after Stress Urinary Incontinence Surgery. Obstetrics \& Gynecology, 120, 83-90. https://doi.org/10.1097/AOG.0b013e318258fbde

[16] Garely, A.D. and Noor, N. (2014) Diagnosis and Surgical Treatment of Stress Uri- 
nary Incontinence. Obstetrics \& Gynecology, 124, 1011-1027. https://doi.org/10.1097/AOG.0000000000000514

[17] Petros, P. (2015) Creating a Gold Standard Surgical Device. International Urogynecology Journal, 26, 471-476. https://doi.org/10.1007/s00192-015-2639-3

[18] Rajan, S. and Kohli, N. Retropubic Hematoma after Transobturator Sling Procedure. Obstretrics\& Gynecology, 106, 1199-202.

[19] Zong, W.J., et al. (2010) Alteration of Vaginal Elastin Metabolism in Women with Pelvic Organ Prolapse. Obstetrics \& Gynecology, 115, 953-961.

https://doi.org/10.1097/AOG.0b013e3181da7946

[20] Bourdreaux-Nippert, D., et al. (2006) Manufacturer and User Facility Device Experience (MAUDE) Database to Identify All Complications Reported with the Use of TOT.

[21] Murphy, A.M., et al. (2013) Treatment of Overactive Bladder: What Is on the Horizon. International Urogynecology Journal, 24, 5-13.

[22] Muir, T., Tulikangans, P.K., et al. (2003) The Relationship of Tension-Free Vaginal Insertion and Vascular Anatomy. Obstetrics \& Gynecology, 101, 933-936.

[23] Ball Jr., T., Teichman, J., Sharkey, F., et al. (1997) Terminal Nerve Distribution to the Urethra and Bladder Neck: Considerations in the Management of Stress Urinary Incontinence. Journal of Urology, 158, 827-829.

https://doi.org/10.1016/S0022-5347(01)64329-5 